\title{
Semantic Web based e-Learning System for Sports Domain
}

\author{
S.Muthu lakshmi \\ Research Scholar \\ Dept.of Information Science \& Technology \\ Anna University, Chennai
}

\author{
G.V.Uma \\ Professor \& Research Supervisor \\ Dept.of Information Science \& Technology \\ Anna University, Chennai
}

\begin{abstract}
This paper presents an approach for developing a semantic web based e-learning system for sports domain. It involves RDF, ontology model and web ontology language. This paper discussed different type of sports and learner-instructor communication through elearning.
\end{abstract}

\section{Keywords}

e-learning, ontology, RDF, semantic web, Tutor and leaner framework.

\section{INTRODUCTION}

In an e-learning system, the presentation of the content could reach e-learner easily. The content presented has to be authenticated and attractive. Multimedia presentation, animated texts, animated clips, visual effects with sounds have more impact in a learner than conventional methods.

e-learning is being increasingly viewed as an important activity in the field of distance and continuing education. Semantic Web-based courses offer advantages for learners by making access to educational resources, at any time or place. It can be described as "formal or informal learning and training activities,processes, communities and events by the use of electronic media.

In sports domain, multimedia, animation, visual effects with sounds can facilitate an efficient learning environment for the e-learners. The efficiency of the system depends on the delivery of comprehensive. Dynamic learning content to each individual in real time. Development of knowledge for the learners and practitioners is enhanced.

Semantic Web is the Expression of Meaning-Content authoring. E-learning is a web based technology for the learner by the learning process, video conferencing etc. The direct relation of Semantic Web and E-Learning combines the traditional content authoring process with the critical objective of meaningful expression. Now a days Semantic Web based learning is advantageous for learners, since it gives instant access to educational resources, round the clock at any place.

Ontology is a specification of a conceptualization. Conceptualization is a simplified view of the world that represents the purposes. Ontology for the e-learning process can be set up in different ways. Every ontology will include a dictionary with explanation of the terms and indications, how the terms are related to one another. This approach will give a valid tool for the learning process. The ontologies represent conceptual description of the specific content as they help to identify appropriate items and relationships in a given knowledge domain. As ontologies show a hierarchical dependence of the terms together with descriptions, explanations and definitions. New user such as students as well as software agents will be able to understand use and incorporate the concepts in the underlying a knowledge domain. Ontology gives graphical representation by ontoviz and owlviz.

\section{RELATED WORK}

Danuvasin Charoen[2], he examines the issues related to the implementation of e-Learning at the National Institute of Development Administration (NIDA). The effort of Fayed Ghaleb and others in [3], propose an approach for developing a Semantic Web-based e-learning system, which focus on the RDF data model and OWL ontology language. They have demonstrated the effectiveness of this approach in architecture offering semantic-based services to students and tutors. In particular ways to browse and obtain information through web services.

Domain ontology proposed in [5] virtual classroom domain using questionnaire, emphasis is more on the adaptive learning environment to facilitate sharing and reusing of learning materials. In addition 
to this three adaptation processes are presented in the learning environment: Course based adaptation, Concept based adaptation and Goal based adaptation.

The paper by Kiu, presented an ontoDNA framework for automated ontology mapping and merging which helps in dynamic updation of the knowledge base with the new ontologies in [4]. And also there was a model to merge knowledge management system with school administration system, to improve routines in traditional classrooms to improve knowledge communication and sharing process. Some authors investigated whether congruities between students' learning styles and instructors' teaching styles related to student satisfaction. This proposed paper uses enlightened that ontoDNA helps in interoperability between standards and schemas which enhances learning and teaching.

The e-learning management systems are integrated systems that support a number of "teachers" and "students" in web-based learning system education. Learning management systems enable teachers to compose their courses newly created and existing elearning material[9]. E-learning is represented as a wide range of application, ranged from visual class rooms to remote courses. Ontology is a specification of conceptualization. The object process and other entities that are involved in making of the framework for elearning. This paper presents the ontology for e-learning process, such as course syllabus, teaching methods, learning activities and learning styles especially for Indian learning environment. Ontology for the e-learning processes can be set up in various ways but ontology will include a dictionary with explanation of the terms, and indications how the terms are related to another [1]. A web based e-learning system using semantic web framework present a framework for web based elearning system using the semantic web technology, which focus on the RDF data model and web ontology language and RAP parsing RDF documents[6].

Personalized Learning Material Generation System is proposed to personalize the lessons, exercises and tests keeping the semantic and structural coherence for every subject and each student who have entry to this system. This system is similar to the proposed system in a way that this too is a learner-instructor based system [7].

\section{RESOURCE DESCRIPTION FRAMEWORK}

The Ontology document is presented in the RDF languages. The RDF data model[8] is based on a Class diagrams, as it is based upon the idea of making statements, about resources in the form of subject-predicate-object expressions. These expressions are known as triples in RDF terminology. The subject denotes the resource, and the predicate denotes aspects of the resource and expresses a relationship between the subject and the object. For example, one way to represent the notion "All Players are Coaches" in $\mathrm{RDF}$ is as the triple: a subject denoting "All Players", a predicate denoting "are", and an object denoting "Coaches". RDF is an abstract model with several serialization formats, and so the particular way in which a resource or triple is encoded varies from format to format [8].

RDF Triples example: Tendulkar Plays Cricket

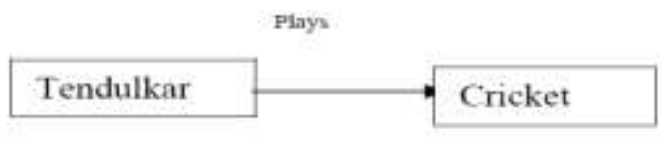

Fig 1.RDF statement

RDF statement Fig 1. Explains the combination of Subject, Predicate and Object. Here Tendulkar is the Subject and plays is the predicate and Cricket is the object.

\subsection{Learner and Instructor Relationships}

The relationship between the number of instructor and the number of Learner was found to be of statistical significance.

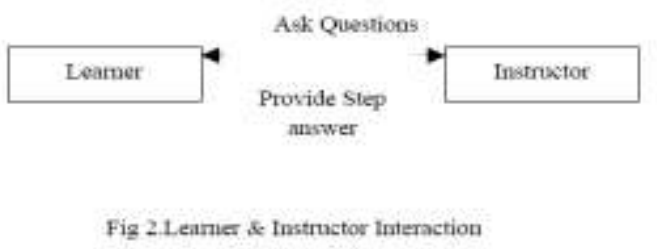

Fig. 2 Explains the communication between the learner and instructor modules. Learner query their doubts to the instructor through e-mail or video conference. Instructor responds the learner's queries and writes them with step by step answers.

\subsection{Classification of Ontology Domain}

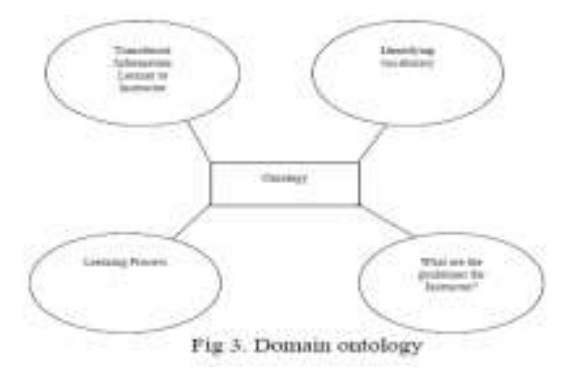


Fig 3. Explains the domain ontology, which describes the meaning of the identified vocabularies.

\section{FRAMEWORK FOR SPORTS DOMAIN}

Sports domain framework Fig. 4 consists of service, elearning and knowledge, etc as shown in below

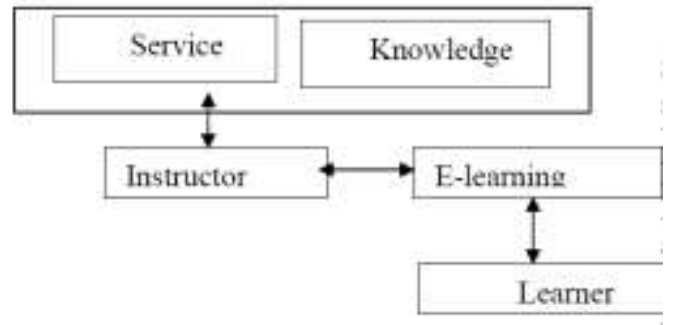

Fig-4 5ports Doinain Framework

Learner enquires about the level of events. Instructor provides some exercises to the learner based on his ability. Learner works out the exercises given by the instructor. Instructor searches the event through service and knowledge. Instructor assigns marks for the performance and starts coaching through chat, e-mail or video conference.

\subsection{Architecture of semantic web based sports domain}

Fig 5. describes the Architecture based on the Semantic Web Technology and E-Learning.

Service based model: It includes three service models namely, Instructor service, Learner service, Sports service. Instructor service includes instructor name, Place of coaching, Awards, Coaching fee and contact number and e-mail id; Learner service includes registration and login, how many matches played and participated, awards won, place of coach; Sports service includes Who is the organizer of the sports and venue for sports and events, Date and Time of sports, how to register

Knowledge based Model: It includes Students database, Resource Description Framework, Ontology. In ontology bottom level is text and image of the learner levels, Student records maintain the whole student details.

e-learning based Model: In this model, Instructor enquires about learner, since search engine understands the instructor query, it searches for the knowledge base model. Search engine displays relevant information about learner query. Instructor evaluates the learner skill and coach to the learner accordingly. Learner sends the query to instructor through e-learning model. The instructor assumes the learner query and gives some exercise to learner. The learner workout the exercise and sends to the instructor. Instructor analyses the learner performance and coaches to the related event. The search engine searches the related information and infers the event through e-learning.

\section{IMPLEMENTATION}

\subsection{Ontology for Sports Domain}

E-Learning ontology which is briefly depicted in this section comprises of concepts definition, their interrelation that are necessary to develop sports domain in the e-learning. A series of sub-ontologies with their corresponding vocabularies can be used to describe the instances of the most basic classes in detail. The learner sends the queries to the instructor. He finds the corresponding instructor and determines the various field details. In turn integrates elearner needs to learn the process from the instructor, instructs the step by step process of the corresponding events.

At the same time as these ontology languages have been developed, tools have emerged for creating, editing and managing ontologies written in the various languages

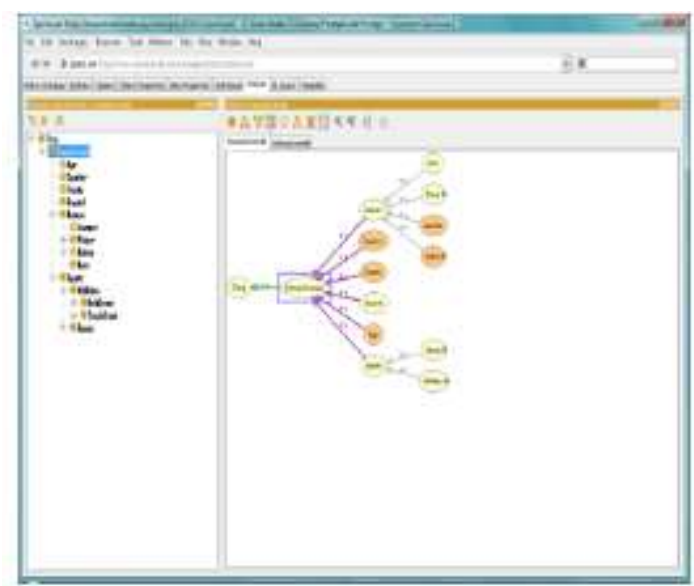

Fig 6. shows a small ontology being created using Protégé's interface.

In this example, several instances of the class "sports" have been defined, including, type of sports 
systems, player details and instructor details. Any "slots" (attributes) can be defined - in this case, each instance has a name and three potential relations to other instances (Has Part, Requires and Suggested Order). "Forms" allow the user interface for entering ontology information. "Queries" allow the ontology to be searched based on the attributes of instances. The Ontoviz plugin allows ontologies to be viewed graphically; such visualisation tools can be helpful in the development process.

\subsection{Applicability of e-learning for sports domain}

\section{ANALYSI OF VARIANCE (ANOVA)}

In this analysis, assume that there are ' $n$ ' instructors and two group of students, e-learning and d-learning. The analysis measure the efficiency of the instructors based on the performance of the students. An instructor is assigned to one student from each group for measuring the performance. The related data for the selected instructors $(n=10)$ is shown in the table 1 .

\begin{tabular}{|c|c|c|c|c|c|c|c|c|c|c|}
\hline $\begin{array}{c}\text { Instructors ( Learning } \\
\text { Metbods }\end{array}$ & \multicolumn{10}{|c|}{ Students Performance $(\%)$} \\
\hline Instructors & II & I2 & 13 & I4 & 15 & 16 & 17 & 18 & 19 & 110 \\
\hline D-Leaming & 46 & 76 & 56 & 67 & 72 & 67 & 60 & 45 & 69 & 42 \\
\hline E-leaming & 90 & 80 & 65 & 56 & 50 & 90 & 78 & 93 & 89 & 67 \\
\hline Table 1. Performance ( $\%$ ) of Students in different learning metbods under \\
different Instructors \\
\hline
\end{tabular}

The reason behind selecting variance analysis is that there exists a linear relationship between different learning methods. In order to measure the performance of various instructors. There are two different learning methods, variance analysis is chosen to compare the efficiency of the students belonging to these groups.

ANOVA is an analysis of the variation present in an experiment. It is a test of the hypothesis that the variation in an experiment is not greater than that due to normal variation of individuals, characteristics and error in their Measurement. In this work, ANOVA is used for analysing the variation that occurs between the Distance learning and e-learning techniques.
Generally, F-test is a statistical test in which the test statistic has an F-distribution under the null hypothesis. It is often used when comparing statistical models that have been fit to a data set, in order to identify the model that best fits the population from which the data were sampled. Exact F-tests mainly arise when the models have been fit to the data using least squares. While finding the variations between the T-test and F-test learning methods have to be identified.

\subsection{Parameters of performance measurement}

Each learning method has its own parameters for measuring the performance. The parameters of D learning method are attendance of contact programme, submission of assignments, marks scored in the cycle tests and marks scored in the final exam.

ANOVA is an analysis of the variation present in an experiment. It is a test of the parameters of Elearning method are contact session attendance, submission of on-line assignment, marks secured in the cycle test, and marks secured in the final exam. The weightage for each of the parameters can be taken, depending upon the importance of the parameters. Table 2 shows the weightage of the parameters.

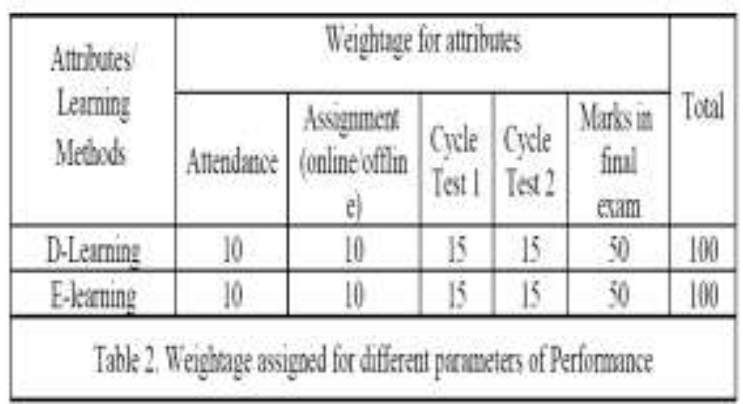

(1) Correction Factor $(\mathrm{CF})=\mathrm{S} 2 / \mathrm{N}$

$=(1358) 2 / 20=1844164 / 20=92208.2$.

(2) Total sum of squares = Ó Óxij

$2-\mathrm{CF}=96944-92208.2=4735.8$

with degrees of Freedom $=2 \times 10-1=19$.

(3) Sum of squares between capacities of learning methods $=(934564 / 10)$ -

$92208.2=1248.2$ with degrees of

Freedom $=2-1=1$. 
(4) Sum of squares between Instructors $=(187068 / 2)-$ $\mathrm{CF}=93534-92208.2=$

1325.8 with degrees of Freedom $=10-1=9$.

(5) Residual sum of squares $=(2)-(3)-(4)=4735.8-$ $1248.2-1325.8=$

2161.8 with degrees of Freedom $=(2-1)(10-1)=9$.

Tabulated value of F5\% for d.f. $(1,9)$ is 5.12, which is less than the calculated value of F, 5.19. That is, calculated value of $\mathrm{F}$ is just greater than the tabulated value. Tabulated value of F5\% for d.f. $(9,9)$ is 3.23 , which is much greater than the calculated value of $\mathrm{F}, \quad$ 0.61.That is, calculated value of $\mathrm{F}$ is much less than the tabulated value.

\section{ANOVA TABLE.}

\begin{tabular}{|c|c|c|c|c|c|}
\hline $\begin{array}{l}\text { Source of } \\
\text { Varation }\end{array}$ & $\begin{array}{l}\text { Sum of } \\
\text { Squares }\end{array}$ & $\begin{array}{l}\text { Degress } \\
\text { of } \\
\text { freediven }\end{array}$ & $\begin{array}{l}\text { Estimation } \\
\text { of Varation }\end{array}$ & $\begin{array}{l}\text { Calcularad } \\
\text { F Valase }\end{array}$ & $\begin{array}{c}\text { Tabulated } \\
\text { F Value at } 5 \%\end{array}$ \\
\hline $\begin{array}{l}\text { Between } \\
\text { lencring } \\
\text { methods }\end{array}$ & 1248.2 & 1 & $\begin{array}{r}1248.27= \\
1248.2\end{array}$ & $\begin{array}{r}12+82240.2- \\
519 \\
\end{array}$ & df $(1,9)-5.12$ \\
\hline $\begin{array}{l}\text { Between } \\
\text { Instructars }\end{array}$ & 1325.8 & 9 & $\begin{array}{r}1325.89- \\
147.31 \\
\end{array}$ & $\begin{array}{c}14731 / 240.2= \\
0.6 ! \\
\end{array}$ & d $f(9,9)-3.23$ \\
\hline Ressitual & 2161,8 & 9 & $\begin{array}{r}2161.89= \\
240.2\end{array}$ & & \\
\hline Total & 4735.8 & 19 & . & & \\
\hline
\end{tabular}

Therefore, the difference between understanding capability of learning

methods is not significant. The difference between the performance of instructors is significant. The variance between learning methods is very small which shows that there are no significant differences in the understanding capabilities between D-learning

method and E-learning method. There exists a huge variation between the efforts of instructors as shown the graph detailed below:

Performance Comparison Graph

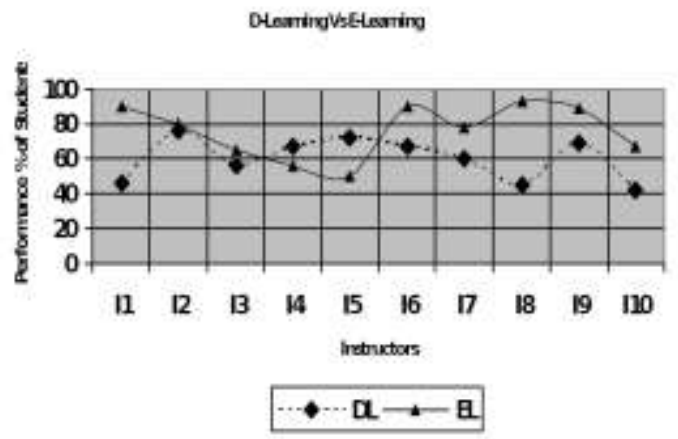

\section{CONCLUSION}

This paper discussed the basic issues of a learner system in the e-learning domain. Use of the ontology techniques to improve the concept of ontology and relationship among ontologies. The ground details and event details and learning objects, online service providers, content details, learner details, are discussed. This e-learning ontology provides the needed semantics for the learner of sports domain. Future Plans are there to extend this paper work to Query template which will be useful for data extraction.

\section{REFERENCES}

[1] Hafiz Waqas Malik(2009) .Visual semantic Web: Ontology Base e-Learning Management System.

[2] Danuvasin Charoen(2009). Challenges and Opportunities of eLearning: A Case Study of Higher Education in Thailand, Americas Conference on Information Systems.

[3] Fayed Ghaleb, Sameh Daoud, Ahmad Hasna, Jihad M. ALJa'am, Samir A(2006). El- Seoud, and Hosam ElSofany, "E-Learning Model Based On Semantic Web Technology", Vol. 4, No. 2.

[4] Kiu, C.-C., \& Lee, C.-S(2006). Ontology Mapping and Merging through OntoDNA for Learning Object Reusability, Educational Technology \& Society, 9 (3),

27-42.

[5] Henze, Dolog, P, \& Nejdl, W(2004). Reasoning and Ontologies for Personalized E-Learning in the Semantic Web.Educational Technology \& Society, 7 (4), 82.

[6] Fayed Ghaleb, Sameh Daoud, Ahmad Hasna, Jihad Jaam, Samir A. El- Seoud, and Hosam El-Sofany(2007) A Web-Based E-Learning System Using Semantic Web Framework, Journal of Computer Science 2 (8): 619-626.

[7] Ozlem Cakir Balta, Nurettin Simsek, and Nezaket Tezcan Dr. Cakir Balta(2009) ,A Web Based Generation System for Personalization of E-Learning Materials, world Academy of Science, Engineering and Technology 49.

[8] Frank Manola, Eric Miller, Resource Description Framework (RDF): concepts and abstract syntax, 10 February 2004, http://www.w3.org/TR/2004/RECrdfprimer-20040210.

[9] Chakkrit Shae and Michael Bruckher(2007). Ontology Driven e-Learning System Based on Roles \& Activities for Thai Learning Environment, Interdisciplinary Journal of Knowledge and Learning Objects, Volume 3 